\title{
Capillary earlobe blood may be used for RNA isolation, gene expression assays and microRNA quantification
}

\author{
UDO F. WEHMEIER and THOMAS HILBERG
}

\author{
Department for Sports Medicine, University of Wuppertal, Wuppertal D-42285, Germany
}

Received February 26, 2013; Accepted August 29, 2013

DOI: $10.3892 / \mathrm{mmr} .2013 .1779$

\begin{abstract}
An increasing number of studies examining gene expression associated with diseases in children is likely, in the near future, to provide simple and easy to use methods for the isolation of RNA for gene expression profiling. Prerequisites for such studies are likely to encompass the use of small amounts of blood, as well as less invasive blood collection methods. In the current study, RNA was isolated from $20 \mu$ l capillary blood samples from the earlobes of 10 adults for quantitative PCR experiments. The results were compared with RNA isolated from venipuncture samples of the 10 samples. The expression of 4 mRNAs and 1 microRNA (miRNA), miRNA-126, was measured. The quantitative PCR results obtained with the capillary blood probes were similar to results using venous blood samples. The few differences observed may result from a variation in the blood cell composition. The use of capillary blood samples from the earlobe for gene expression analysis is likely to allow this method to be used in newborns, babies and children. In addition, such a method, using microliters of blood samples, may also be useful for other medical studies e.g., in cases where repetitive blood sampling is necessary or in patients with bleeding disorders.
\end{abstract}

\section{Introduction}

Gene expression profiling has revolutionized research in the past decade, particularly with the advent of microarrays. Expression profiling of selected RNAs may also be a potentially promising substrate for the detection, tracking and prediction of diseases, since a number of RNAs may be detected in the blood. Liu et al (1) have shown in rat models that differential genomic expression patterns for epilepsy, stroke and trauma are common in the brain and blood. Unique mRNA expression patterns were measurable, for example in patients with

Correspondence to: Dr Udo F. Wehmeier, Department of Sports Medicine, University of Wuppertal, Pauluskirchstrasse 7, Wuppertal D-42285, Germany

E-mail: wehmeier@uni-wuppertal.de

Key words: capillary blood, venous blood, RNA isolation, quantitative PCR, gene expression neurofibromatosis type 1 and tuberous sclerosis complex type 2 (2). Blood mRNA expression patterns were identified as a biomarker for acute migraine, medication overuse headaches and menstrual-related migraine (3-5). Gene expression profiling is also used in pediatrics more often under specific conditions. For example, Jacobo-Albavera et al (6) showed that VNN1 gene expression levels and the G-137T polymorphism were associated with HDL-C levels in Mexican prepubertal children. Greiner et al (7) analyzed mRNA blood expression patterns in new-onset idiopathic pediatric epilepsy.

There is a requirement to establish less invasive methods for extracting blood samples for routine gene expression profiling in children, particularly in newborns or in individuals with bleeding disorders. Less invasive methods are also required in sports medicine, where serial sampling is often necessary to monitor the effects of exercise. At present, venipuncture blood samples are used in the aforementioned studies (2-7). However, limitations exist on the extraction methods of RNA from small plasma/serum samples. Significant improvements have been made with regard to whole blood RNA isolation techniques. The majority of human whole blood RNA stabilization/isolation kits require venous blood samples of a minimum of $0.5 \mathrm{ml}$, usually acquired by venipuncture samples. Medical applications using capillary blood include the monitoring of blood glucose to test bacterial infections, e.g., Helicobacter pylori $(8,9)$ and to determine cholesterol $(10,11)$ and other parameters. Capillary blood from fingertips was used for these tests. In 2009, a method using $70 \mu \mathrm{l}$ blood obtained from the fingertips and modified instructions of the commercially available Qiagen PAXgene RNA Blood kit was described (12).

In sports medicine, the use of small volumes of capillary blood is well established and routinely used for lactate diagnostics. Generally, capillary blood is obtained from earlobes using end-to end capillaries, which is less invasive. The current study aimed to establish a method using end-to end capillaries to sample probes for gene expression analysis. A simple method to isolate RNA from $20 \mu$ l capillary blood samples obtained from the earlobe using end-to end capillaries was used and the results obtained in quantitative PCR approaches with RNA isolated from venous blood were compared. The expression of a standard housekeeping gene, GAPDH, the cholesterol receptor gene CD36, the creatine kinase genes, CK-MM and CK-MB and the arginase genes ARG1 and ARG2, which are putative exercise relevant markers in sports medicine and 
which may also be used to show overtraining in children, were examined. In addition, microRNAs (miRNAs) in capillary blood was determined. miRNAs are often transported as free molecules in blood (13) or observed to be bound to HDL (14), thus becoming increasingly important for regulatory networks. miRNAs are likely to play a dominant role in future studies in widespread diseases, including diabetes, heart failure or other cardiovascular diseases and may be a tool for preventional diagnostics in future.

In the current study, the gene expression profile from venous and capillary blood samples of 10 adults were compared to evaluate the proposed method, which is likely to be a promising tool, particularly in pediatric diagnostics where less invasive methods are required or in sports medicine and training diagnostics.

\section{Materials and methods}

Chemicals. All chemicals used were of per analysis (p.a.) quality and were of commercial origin from various suppliers. The TrioMol reagent was obtained from Genscript, USA and the TriFast reagent from PeqLab (PEQLAB Biotechnologie $\mathrm{GmbH}$, Erlangen, Germany).

Test individuals and blood samples. 10 test individuals were included in the current study; 5 female (age, 23-46 years) and 5 male (age, 25-49 years). Venous blood was obtained using standard EDTA monovettes (Sarstedt, Hildesheim, Germany). Capillary blood samples were obtained from the earlobes of the test individuals using $20 \mu \mathrm{l}$ capillaries. For comparative experiments, venous blood was obtained at the same time to avoid time-dependent differences in the expression profiles. The study was approved by the Ethics Committee of the University of Wuppertal (Wuppertal, Germany) and written informed consent was obtained from the patients.

RNA isolation. The isolation of total RNA from the blood samples followed the instructions of use for the TrioMol or the TriFast reagents. Blood samples $(20 \mu 1)$ were mixed with $1 \mathrm{ml}$ TrioMol reagent by vortexing for $\sim 15 \mathrm{sec}$. Then the RNA was isolated directly following the instructions for the TrioMol reagent or the probes were frozen at $-80^{\circ} \mathrm{C}$ for later preparation. To isolate the RNA, $200 \mu \mathrm{l}$ chloroform was added, the mixture was vortexed, incubated for $\sim 5 \mathrm{~min}$ at room temperature and centrifuged at $15,000 \mathrm{x} \mathrm{g}$ for $15 \mathrm{~min}$. The upper phase was collected, transferred to a new tube with $500 \mu 1$ isopropanol and mixed by inverting. Following incubation for a minimum of $5 \mathrm{~min}$ at room temperature, the probes were centrifuged at 15,000 x g, the supernatant was discarded and $1 \mathrm{ml} \mathrm{70 \%} \mathrm{ethanol,} \mathrm{prepared} \mathrm{with} \mathrm{DEPC-treated}$ distilled water, was added and the probes were centrifuged at $15,000 \mathrm{x} \mathrm{g}$ for $15 \mathrm{~min}$. The supernatant was carefully removed, the pellet was dried at $60^{\circ} \mathrm{C}$ for $\sim 15 \mathrm{~min}$ and $40 \mu 1$ RNAse free water was added. The solution was maintained for $15 \mathrm{~min}$ at $60^{\circ} \mathrm{C}$. The RNA solutions were usually stored at $-80^{\circ} \mathrm{C}$. The purity and RNA content of the RNA samples was controlled in a photometer (Genesys10, Thermo Fisher Scientific, Waltham, MA, USA). The contamination of proteins was controlled by measuring the $\mathrm{OD}_{260 / 280}$ and contaminants were excluded by measuring $\mathrm{OD}_{260 / 230}$ ratio.
PGTX solution. The preparation of PGTX solution was described by Pinto et al (15). The PGTX solution has the following composition (for a final volume of $100 \mathrm{ml}$ ): phenol (39.6 g), glycerol (6.9 ml), 8-hydroxyquinoline (0.1 g), EDTA $(0.58 \mathrm{~g})$, sodium acetate $(0.8 \mathrm{~g})$, guanidine thiocyanate $(9.5 \mathrm{~g})$, guanidine hydrochloride (4.6 g) and Triton X-100 (2 ml), with a final $\mathrm{pH}$ of 4.2. At room temperature, the PGTX extraction mixture forms a monophasic solution. Two variants of preparing this solution were tested. For variant 1, all components were weighed, water was added to $100 \mathrm{ml}$ and the solution was stirred at $50-60^{\circ} \mathrm{C}$ to produce a homogenous solution. PGTX variant 1 formed a monophasic solution at room temperature, but when it was stored at $4^{\circ} \mathrm{C}$ it appeared biphasic. Following warming to room temperature, the variant became monophasic again. PGTX variant 2 was obtained in the following way: phenol was slowly heated until it melted completely. The other reagents were dissolved in $\sim 40 \mathrm{ml}$ distilled water and then added to the liquid phenol. The volume was filled to $100 \mathrm{ml}$ with water. This solution remained monophasic following cooling to $4^{\circ} \mathrm{C}$.

Quantitative PCR with SYBR Green. The quantitative PCR tests were performed in a StepOne real time PCR unit (Applied Biosystems, Beijing, China) using the Power SYBR Green RNA-to-CT 1 step kit (Applied Biosystems) in 48-well plates according to the manufacturer's instructions. The reaction mixture $(20 \mu \mathrm{l})$ contained $0.16 \mu \mathrm{l}$ RT Enzyme Mix, $10 \mu \mathrm{l}$ RT-Mix, $100 \mathrm{nM}$ of each primer and $2 \mu \mathrm{l}$ sample and each probe was tested in a duplicate. Commercially available human standard RNA (Applied Biosystems) was included as a control template in each quantitative PCR and served as an internal standard. Non-template controls for each primer pair were included. Quantitative PCR was performed under the following conditions: $48^{\circ} \mathrm{C}$ for $30 \mathrm{~min}, 95^{\circ} \mathrm{C}$ for $10 \mathrm{~min}$, then 40 cycles with $95^{\circ} \mathrm{C}$ for $15 \mathrm{sec}$ and $60^{\circ} \mathrm{C}$ for $1 \mathrm{~min}$. Following the final cycle, the melt curves of the PCR products were determined to verify the integrity of the PCR products. For the comparison of the real time assays the $\mathrm{C}_{\mathrm{T}}$ values were determined using the standard settings of the StepOne software package (version 2.1; Applied Biosystems).

Primer design and sequences. The primers used were designed using the primer3plus program (http://www.bioinformatics. nl/cgi-bin/primer3plus/primer3plus.cgi). To prevent undesirable amplification of DNA contaminations, the primers were designed to include the junction of the two exons, which is not present in the DNA or so that they were located on two exons. The primers are listed in Table I and the expression of the following genes were determined: glyceraldehyde-3-phosphate-dehydrogenase (GAPDH) as the control gene, the gene CD36 encoding a scavenger receptor, the creatine kinase genes CK-MM (muscle type) and CK-MB (brain type), the two were detected together with the same primer pair (see Table I), the hepatitic arginase gene ARG1 and the mitochondrial arginase gene ARG2.

TaqMan MicroRNA assays. The TaqMan MicroRNA assays (Applied Biosystems) were applied for the detection of miRNA-126. The assays were performed as recommended by the manufacturer. In the reverse transcription step, cDNA was 
Table I. Sequences of the primers used in the quantitative PCR assays.

\begin{tabular}{lll}
\hline mRNA & \multicolumn{1}{c}{ Forward primer } & \multicolumn{1}{c}{ Reverse primer } \\
\hline GAPDH & 5'-CGGAGTCAACGGATTTGGTCG-3' & 5'-AGCCTTCTACATGGTGGTGAAGAC-3' \\
CD36 & 5'-GCCAGTTGGAGACCTGCTTA-3' & 5'-CAGCGTCCTGGGTTACATTT-3' \\
CK & 5'-CCAGGTTGGATGGGCA-3' & 5'-GGGCAACATGAAGGAGGT-3' \\
ARG1 & 5'-GGAGACCACAGTTTGGCAAT-3' & 5'-CCACTTGTGGTTGTCAGTGG-3' \\
ARG2 & 5'-TGGCTTGATGAAAAGGCTCT-3' & 5'-TAACCACCTCAGCCAGTTCC-3'
\end{tabular}

${ }^{\mathrm{a}} \mathrm{CK}$ genes CK-MM (muscle type) and CK-MB (brain type) are 79\% identical. The primers CK-F and CK-R allowed the common detection of the two transcripts, yielding PCR products covering the region from bases 153-301 of the CK-MM RNA and the region 140-288 of the RNA from CK-MB, respectively. CK, creatine kinase; ARG, arginase.

reverse transcribed from total RNA ( $5 \mu$ l of the isolated RNA was applied in a $15 \mu \mathrm{l}$ assay) using a Personal Cycler from Biometra (Göttingen, Germany). A total of $1 \mu \mathrm{l}$ from the RT reaction was used for the $\mathrm{PCR}$ reaction in a total volume of $20 \mu \mathrm{l}$. In the PCR step, PCR products were amplified from cDNA samples using the TaqMan MicroRNA assay together with the TaqMan Universal PCR Master Mix using a StepOne real time PCR unit (Applied Biosystems).

\section{Results}

Establishing a method for RNA isolation from capillary blood samples. To establish a versatile method, which is likely to be feasible to obtain small blood samples by capillaries, a number of prerequisites should be fulfilled. The volume of the solution for sampling, the blood probes should be variable and large enough to resolve the total sample from the end-to-end capillary efficiently by shaking. The cells should be lysed immediately and also RNA degrading and modifying enzymes must be inhibited. In addition, the solution should allow freezing of the samples for subsequent analysis. These prerequisites are fulfilled by phenol-based reagents. Therefore, the study aimed to determine the feasibility of isolating RNA from earlobes in $20 \mu \mathrm{l}$ capillaries using the TrioMol and/or TriFast reagents. In the first series of experiments, blood samples were obtained routinely, in the same manner for blood samples for lactate measurements using standard $20 \mu \mathrm{l}$ heparin-coated capillaries. However, as it is possible to isolate RNA in suitable amounts as determined by $\mathrm{OD}_{260 / 280}$ measurements, all approaches to detect any transcript failed. The heparin from the capillaries was washed out and co-eluted with the RNA, thus inhibiting reverse transcription and also the PCR reaction. Similar effects have been observed previously $(16,17)$. Therefore, EDTA-coated capillaries (Sarstedt) were used in the following experiments. The blood filled capillaries were placed immediately into Eppendorf tubes with $1 \mathrm{ml}$ of the reagent and agitated. This step is analogous to the first step in sampling blood for lactate testing and does not require special equipment. At this stage, the probes may be frozen for subsequent RNA preparation. RNA from $20 \mu \mathrm{l}$ capillaries was isolated in $40 \mu \mathrm{l}$ sterile RNAse-free water.

No differences in the RNA levels isolated from $20 \mu \mathrm{l}$ blood samples were detected when the TrioMol and TriFast reagents were compared (data not shown). In addition, the PGTX solution (15) was examined, which is quite similarly composed of the commercially available reagents. In the quantitative PCR assays using PGTX-isolated RNA, almost identical expression results were observed, when compared with RNA isolated with the TrioMol or TriFast reagent (data not shown). The use of the PGTX solution may reduce the costs of such analysis.

Comparison of the gene expression of a number of putative exercise-relevant genes in capillary versus venous blood samples. To the best of our knowledge, comparative gene expression from capillary and venous blood has not been described previously. Therefore, whether the gene expression data from capillary and venous blood is likely to yield similar results was examined. Blood samples were obtained from 10 individuals (male and female, aged 22-49 years) from the earlobe in $20 \mu \mathrm{l}$ capillaries and venous blood using EDTA monovettes. From the venous blood, only $20 \mu \mathrm{l}$ was used for the isolation of RNA. The RNA isolated from earlobe and venous blood was dissolved in $40 \mu \mathrm{l}$ RNAse free water and $2 \mu \mathrm{l}$ from each probe was used for quantitative PCR assays, as described in Materials and methods. For additional control assays, RNA was isolated from $<200 \mu 1$ venous blood. Finally, the miRNA-126 expression values in the total RNA isolated from capillary or venous blood of the 10 test samples was compared. The assays were performed as described in Materials and methods.

The potential of detecting mRNA from genes associated with cardiovascular diseases or those which are also involved in exercise relevant to biochemical pathways in the blood obtained from earlobes was determined. The genes encoding the creatine kinases CK-MM (AAA96609, muscle type) and CK-MB (AAC31758, brain type) were selected, since they may be detected by the same primer pair provided in Materials and methods. The PCR products reflect the sum of the two transcripts. The genes ARG1 (NM_000045; hepatitic arginase) and ARG2 (NM_001172, mitochondrial arginase) encode the arginases, which catalyze the hydrolysis of urea from arginine, the latest step in the urea cycle. The GAPDH RNA served as an internal reference. The respective transcripts were detected in capillary and venous blood (Fig. 1). The expression values in capillary blood were not $100 \%$ identical to those obtained from venous blood (Table II; Fig. 1). However, the relative 
Table II. $\mathrm{C}_{\mathrm{T}}$ values measured with RNA isolated from venous and capillary blood samples.

\begin{tabular}{|c|c|c|c|c|c|c|}
\hline \multirow[b]{2}{*}{$\mathrm{C}_{\mathrm{T}}$} & \multicolumn{6}{|c|}{ mRNA } \\
\hline & GAPDH & CD36 & CK & ARG1 & $\mathrm{ARG} 2$ & miRNA-126 \\
\hline Venous blood $^{\mathrm{a}}$ & $28.07 \pm 1,39$ & $30.38 \pm 1.22$ & $29.18 \pm 1.81$ & $31.62 \pm 1.37$ & $33.97 \pm 1.31$ & $21.19 \pm 0.76$ \\
\hline Capillary blood ${ }^{\mathrm{a}}$ & $29.04 \pm 0.89$ & $33.24 \pm 1.82$ & $29.17 \pm 1.39$ & $33.23 \pm 1.31$ & $34.92 \pm 0.84$ & $22.04 \pm 0.95$ \\
\hline$\Delta \mathrm{C}_{\mathrm{T}}^{\mathrm{b}}$ & -0.97 & & & & & \\
\hline$\Delta \Delta \mathrm{C}_{\mathrm{T}}^{\mathrm{c}}$ & & -1.9 & 0.98 & -1.0 & 0.09 & 0.12 \\
\hline
\end{tabular}

expression ( $\Delta \Delta \mathrm{C}_{\mathrm{T}}$-values, always referring to the GAPDH standard) provided in Table II showed that the obtained values for the miRNA-126 $\left(\Delta \Delta \mathrm{C}_{\mathrm{T}}, 0.12\right)$ and the ARG2 mRNA $\left(\Delta \Delta \mathrm{C}_{\mathrm{T}}, 0.09\right)$ from capillary blood were identical to venous blood probes. The CK-RNA was even more detectable in the capillary blood samples $\left(\Delta \Delta C_{T}, 0.98\right)$, whereby the mRNAs from ARG1 and CD36 were much better detected in venous blood ( $\Delta \Delta \mathrm{C}_{\mathrm{T}},-1.0$ and -1.9 , respectively). To exclude that the levels of the isolated intact RNAs, which were responsible for the differences, a number of controls were included. While no increase of the expression results was obtained if the RNA amount was doubled (maintaining the reaction volume at $20 \mu \mathrm{l}$ ), the reduction of the RNA to $50 \%$ led to the expected -1 shift of the $\mathrm{C}_{\mathrm{T}}$-values (data not shown). Notably, low expression rates were measured when $200 \mu \mathrm{l}$ blood was used for the isolation of RNA applying $2 \mathrm{ml}$ TrioMol or TriFast solution. From these results, it was concluded that the ratio blood/isolation solution should be in the range of 1:20-1:50 for optimal quantitative PCR results.

\section{Discussion}

The aim of the study was to establish a procedure for the isolation of RNA from small capillary blood samples. Firstly, it was determined that $20 \mu \mathrm{l}$ blood obtained from the earlobes or venous blood provides sufficient material for RNA isolation. The isolated RNA amounts are sufficient for a minimum of 20 quantitative PCR assays. The advantages of using capillary blood is that the method is less invasive, thus, it may be easily adopted for newborns and children and may also be applied for serial probe sampling.

The gene expression rates of RNAs isolated from capillary and venous blood were compared and the venous blood samples served as standards (Table II; Fig. 1). To the best of our knowledge, such a comparison has not been published to date. The expression rates of the transcripts for the genes GAPDH, CK, ARG1, ARG2 and the miR126 were lower when analyzing RNA isolated from capillary and venous blood $\left(\Delta \Delta C_{T} \pm 1.0\right)$, particularly the mRNA for the LDL cholesterol receptor gene, CD36, exhibited greater differences $\left(\Delta \Delta C_{T}-1.9\right)$ in capillary blood. Whether these differences are based on a variable composition of blood cells in capillary and venous blood probes remains unclear. Schalk et al (18) have shown that capillary blood samples contain significantly higher numbers of white and red blood cells, but a lower number of platelets. Such differences may contribute to altered gene expression values measured in these two compartments of blood. The origin of the RNAs isolated from blood samples was not further analyzed in the current study. However, it is hypothesized that free RNAs, which may have been released from injured cells as well as the RNAs from the blood cells, were isolated isolated from the blood samples.

One further difference when comparing capillary blood and venous blood may be that during the probe sampling, the capillary comes in contact with oxygen prior to its transferral to the capillaries and that this may activate a number of degradation processes of RNAs. In a previous study by Robison et al (12), RNA isolated from blood samples from fingerstick $(70 \mu \mathrm{l})$ and venipuncture samples was compared. In this study, results similar to the current study were observed. Robison et al (12) showed that the quality of the RNA from fingerstick and venipuncture samples was identical but the $3^{\prime} / 5^{\prime}$ ratio, as an indicator for RNA integrity and degradation, differed and the synthesis of cDNA was lowered when RNA isolated from fingerstick blood was used. Therefore, the absolute $C_{T}$ values determined in capillary blood may differ slightly when compared with venous blood samples. However, the current data clearly showed that the differences are relatively weak and that the data obtained matched well. The expression rates of the genes ARG1, ARG2 and CD36 were relatively low $\left(C_{T}\right.$ values $\left.>30\right)$ which means that the copy numbers of these RNAs in the blood samples were extremely low. This may indicate that differences in the expression values are preferred when analyzing low expressed targets and may result from the degradation processes described previously (12). miRNA-126 was observed to be involved in angiogenic processes $(19,20)$, in playing a role in the formation of epithelial cells (21) and also in cancer (22) and has become a target involved in a number of cardiovascular diseases $(13,19,20,23)$. It was previously observed that miRNA-126 is downregulated in diabetes type 2 patients (24) and is upregulated by exercise (25). Therefore, miRNA-126 is an example of a promising and 
GAPDH

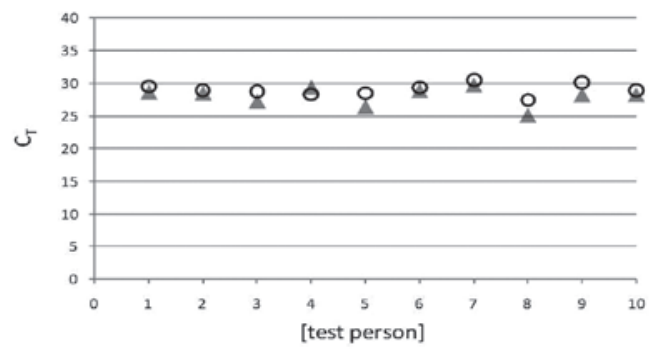

CK

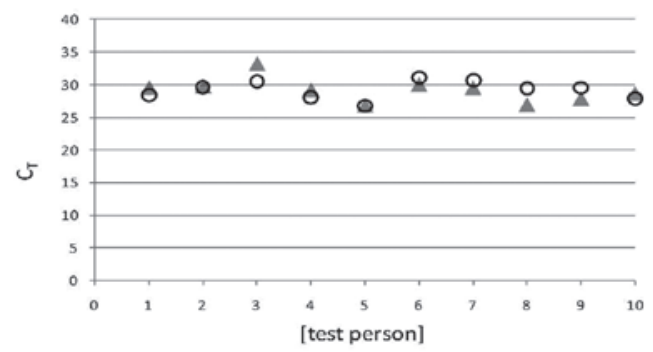

ARG2

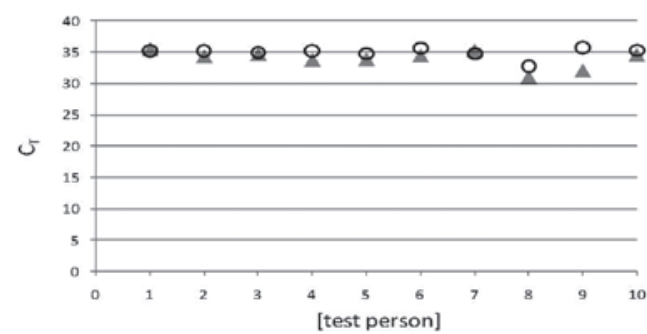

CD36

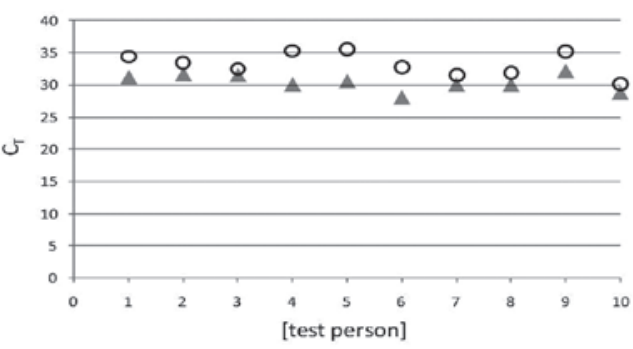

ARG1

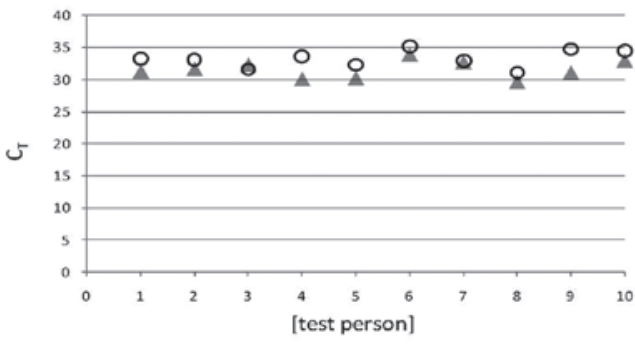

$\operatorname{miR} 126$

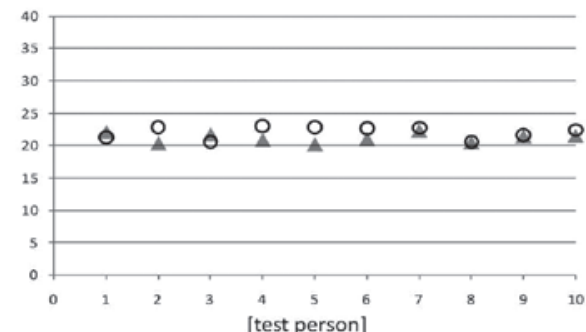

Figure 1. Comparison of quantitative PCR results from 10 individuals using RNA isolated from venous and capillary earlobe blood. RNA from $20 \mu 1$ blood samples was isolated and analyzed using quantitative PCR assays as described in Materials and methods. The RNAs for GAPDH, CD36, CK-MM, CK-MB, ARG1 and ARG2 were detected using the Power SYBR Green RNA-to-CT 1 step kit from Applied Biosystems (Beijing, China). miRNA-126 was detected using the TaqMan MicroRNA assays (Applied Biosystems). Open circles symbolize RNA isolated from capillary blood, grey triangles indicate RNA from venous blood. The numbers on the X-axis indicate the 10 test individuals and equal numbers correspond to the same test individual. The numbers on the Y-axis correspond to the $\mathrm{C}_{\mathrm{T}}$-values as an indicator for the expression rates. Each experiment was performed in duplicate and the expression values shown are the mean values of the two experiments. CK, creatine kinase; ARG, arginase; miRNA, microRNA.

useful target in multiple diagnostic studies. Hence, it may be hypothesized that miRNA testing is likely to become a standard method in the future for a number of diseases and miRNAs are likely to become biomarkers that may be useful for medical precautions. In addition, the comparison of absolute expression levels of specific genes between children and adults are likely to provide novel insights in the future. The current study has shown that miRNA detection from capillary blood is as efficient as miRNA from venous blood and the use of capillary blood is likely to provide an alternative and simple method for probe sampling in routine assays, where only a limited number of miRNAs may be determined. It was previously shown that capillary samples from fingersticks and venous samples of total CK are similar following eccentric exercise, with disagreement between the venous and capillary samples estimated at $>12 \%$ across the ranges of CK values (26). Therefore, it is possible to conclude that the use of capillary blood is likely to provide similar data for a number of enzymatic approaches, as well as for gene expression studies and thus, the application of capillary blood samples is likely to be a useful tool, particularly in the future. This method is currently being applied in a training study with children and the first preliminary data show that gene expression profiling with capillary earlobe blood from children provides promising results (data not shown).

In conclusion, RNA has been shown to be easily isolated from capillary earlobe blood in sufficient amounts for the detection of mRNA or miRNAs. The use of capillary blood samples for gene expression analysis is likely to be a new and promising tool for use in pediatrics, sports medicine and all other medical fields. In addition, such a method based on microliter blood samples may also be useful for studies requiring multiple repetitive blood sampling or with patients with bleeding disorders, where less invasive methods are strictly required.

\section{Acknowledgements}

The authors are grateful to Stefanie Straaten and Holger Stephan for obtaining the blood samples and to Kathleen Menzel for helpful discussions. The members of the Lehrstuhl for Sportmedizin at the BU Wuppertal and the students who 
participated in this study and Esther Wangari for linguistic support are also thanked.

\section{References}

1. Liu DZ, Tian Y, Ander BP, Xu H, Stamova BS, Zhan X, Turner RJ, Jickling $G$ and Sharp FR: Brain and blood microRNA expression profiling of ischemic stroke, intracerebral hemorrhage, and kainate seizures. J Cereb Blood Flow Metab 30: 92-101, 2010.

2. Tang Y, Schapiro MB, Franz DN, Patterson BJ, Hickey FJ, Schorry EK, Hopkin RJ, Wylie M, Narayan T, Glauser TA, Gilbert DL, Hershey AD and Sharp FR: Blood expression profiles for tuberous sclerosis complex 2, neurofibromatosis type 1, and Down's syndrome. Ann Neurol 56: 808-814, 2004.

3. Hershey AD, Tang Y, Powers SW, Kabbouche MA, Gilbert DL, Glauser TA and Sharp FR: Genomic abnormalities in patients with migraine and chronic migraine: preliminary blood gene expression suggests platelet abnormalities. Headache 44: 994-1004, 2004.

4. Hershey AD, Burdine D, Kabbouche MA and Powers SW: Genomic expression patterns in medication overuse headaches. Cephalalgia 31: 161-171, 2011.

5. Hershey A, Horn P, Kabbouche M, O'Brien H and Powers S: Genomic expression patterns in menstrual-related migraine in adolescents. Headache 52: 68-79, 2012.

6. Jacobo-Albavera L, Aguayo-de la Rosa PI, Villarreal-Molina T, Villamil-Ramírez H, León-Mimila P, Romero-Hidalgo S, López-Contreras BE, Sánchez-Muñoz F, Bojalil R, González-Barrios JA, Aguilar-Salinas CA and Canizales-Quinteros S: VNN1 gene expression levels and the G-137T polymorphism are associated with HDL-C levels in Mexican prepubertal children. PLoS One 7: e49818, 2012.

7. Greiner HM, Horn PS, Holland K, Collins J, Hershey AD and Glauser TA: mRNA blood expression patterns in new-onset idiopathic pediatric epilepsy. Epilepsia 54: 272-279, 2013.

8. Harrison JR, Bevan J, Furth EE and Metz DC: AccuStat whole blood fingerstick test for Helicobacter pylori infection: a reliable screening method. J Clin Gastroenterol 27: 50-53, 1998.

9. Laine L, Knigge K, Faigel D, Margaret N, Marquis SP, Vartan G and Fennerty MB: Fingerstick Helicobacter pylori antibody test: better than laboratory serological testing? Am J Gastroenterol 94: 3464-3467, 1999.

10. Sblendorio V, Palmieri B and Riccioni G: Blood cholesterol concentration measured by CR3000: fingerstick versus venous sampling. Int J Immunopathol Pharmacol 21: 729-733, 2008.

11. Warnick GR, Leary ET, Ammirati EB and Allen MP: Cholesterol in fingerstick capillary specimens can be equivalent to conventional venous measurements. Arch Pathol Lab Med 118 1110-1114, 1994.

12. Robison EH, Mondala TS, Williams AR, Head SR, Salomon DR and Kurian SM: Whole genome transcript profiling from fingerstick blood samples: a comparison and feasibility study. BMC Genomics 10: 617, 2009.
13. Gilad S, Meiri E, Yogev Y, Benjamin S, Lebanony D, Yerushalmi N, Benjamin H, Kushnir M, Cholakh H, Melamed N, Bentwich Z, Hod M, Goren Y and Chajut A: Serum microRNAs are promising novel biomarkers. PLoS One 3: e3148, 2008.

14. Vickers KC, Palmisano BT, Shoucri BM, Shamburek RD and Remaley AT: MicroRNAs are transported in plasma and delivered to recipient cells by high-density lipoproteins. Nat Cell Biol. 13: 423-433, 2011.

15. Pinto FL, Thapper A, Sontheim W and Lindblad P: Analysis of current and alternative phenol based RNA extraction methodologies for cyanobacteria. BMC Mol Biol 10: 79, 2009.

16. Al-Soud WA and Rådström P: Purification and characterization of PCR-inhibitory components in blood cells. J Clin Microbiol 39: 485-493, 2001

17. Bai X, Fischer S, Keshavjee S and Liu M: Heparin interference with reverse transcriptase polymerase chain reaction of RNA extracted from lungs after ischemia-reperfusion. Transpl Int 13: $146-150,2000$

18. Schalk E, Heim MU, Koenigsmann M and Jentsch-Ullrich K: Use of capillary blood count parameters in adults. Vox Sang 93: 348-353, 2007.

19. Small EM and Olson EN: Pervasive roles of microRNAs in cardiovascular biology. Nature 469: 336-342, 2012.

20. Wang S, Aurora AB, Johnson BA, Qi X, McAnally J, Hill JA, Richardson JA, Bassel-Duby R and Olson EN: The endothelial-specific microRNA miRNA-126 governs vascular integrity and angiogenesis. Dev Cell 15: 261-71,2008.

21. Fish JE, Santoro MM, Morton SU, Yu S, Yeh RF, Wythe JD, Ivey KN, Bruneau BG, Stainier DY and Srivastava D: miRNA-126 regulates angiogenic signaling and vascular integrity. Dev Cell 15: 272-284, 2008.

22. Meister J and Schmidt MHH: miRNA-126 and miRNA-126*: new players in cancer. ScientificWorldJournal 10: 2090-2100, 2010.

23. Landgraf P, Rusu M, Sheridan R, et al: A mammalian microRNA expression atlas based on small RNA library sequencing. Cell 129: 1401-1414, 2007.

24. Zampetaki A, Kiechl S, Drozdov I, Willeit P, Mayr U, Prokopi M, Mayr A, Weger S, Oberhollenzer F, Bonora E, Shah A, Willeit J and Mayr M: Plasma microRNA profiling reveals loss of endothelial miRNA-126 and other microRNAs in type 2 diabetes. Circ Res 107: 810-817, 2010.

25. Uhlemann M, Möbius-Winkler S, Fikenzer S, Adam J, Redlich M, Möhlenkamp S, Hilberg T, Schuler GC and Adams V: Circulating microRNA-126 increases after different forms of endurance exercise in healthy adults. Eur J Prev Cardiol: Nov 13, 2012 (Epub ahead of print).

26. Knoblauch MA, O'Connor DP and Clarke MS: Capillary and venous samples of total creatine kinase are similar after eccentric exercise. J Strength Cond Res 24: 3471-3475, 2010. 